February 2000

Accepted for publication in the Journal of Economic Theory as of March 12, 2000.

\title{
MONEY WITH IDIOSYNCRATIC UNINSURABLE RETURNS TO CAPITAL ${ }^{*}$
}

\author{
BY MIQUEL FAIG \\ Department of Economics \\ University of Toronto \\ 140 St. George Street, Suite 707 \\ Toronto, Canada M5S 3G6 \\ E-mail: faig@ chass.utoronto.ca
}

Phone: 416-9780308

Fax: 416-9785519

"This paper was previously circulated with the title "The Optimum Quantity of Money Versus the Private Ownership of Capital". I am thankful to Allan Hynes, Angelo Melino, Myrna Wooders for helpful discussions and to three anonymous referees for helpful comments. Also, I am indebted to the assistance of Sonia Laszlo.

RUNNING TITLE: Money with Idiosyncratic Returns. 


\begin{abstract}
This paper extends the income fluctuations problem to an economy with endogenous growth. Individuals, instead of owning an stream of endowments, accumulate capital with an investment irreversibility constraint and face uninsurable idiosyncratic risks to the return to capital. Money provides both a risk diversification and a liquidity role. Balanced growth paths exist despite the increasing dispersion of the wealth distribution. The return to money cannot be equated to the social return to capital unless the government owns the entire capital stock with idiosyncratic risk, and it is capable of operating this stock as efficiently as private agents can. Journal of Economic Literature Classification Numbers: E31, E42, E58.

KEY WORDS: Income fluctuations, uninsurable risk, demand for money, optimum quantity of money.
\end{abstract}




\section{INTRODUCTION}

Virtually all types of capital face idiosyncratic and uninsurable risk. This type of risk is certainly found in human capital and capital invested in privately held firms. Less strongly, it is also found in capital invested in publicly held corporations and residential housing because investors must incur transactions expenses when they need to liquidate these assets. In general, capital and claims on its return are costly to trade because of the market imperfections generated by imperfect information and the costs of writing and enforcing contracts. These trading cost simultaneously lead to an incomplete diversification of idiosyncratic risk and to the demand for a fiduciary asset, such as money, providing to its holders liquidity and a means for self-insurance. Equalizing the return to money to the social return to capital (Friedman's rule on the optimum quantity of money) means that investors prefer money to capital facing idiosyncratic and uninsurable risk. Hence, in a long-run equilibrium where money earns the social return to capital, the government must own all the capital with idiosyncratic and uninsurable risk. Moreover, this equilibrium is only optimal if the government can manage capital as efficiently as private individuals can.

The model advanced in this paper reformulates the income fluctuations problem by Foley and Hellwig [9] and the related monetary model by Bewley [4] to an economy with endogenous incomes and growth. ${ }^{1}$ Instead of owning an stream of endowments as in these earlier papers, individuals own capital. The accumulation of this capital faces an investment irreversibility constraint, and its return has uninsurable idiosyncratic risk. In this environment, money helps to diversify idiosyncratic risks (risk diversification role) and to relax the illiquidity caused by the investment irreversibility constraint (liquidity 
role). Because of this liquidity role, a positive demand for money is very robust. For example, under fairly general conditions, the demand for money survives even when its rate of return is stochastically dominated by the rate of return to capital.

As is typical in monetary models, the model presented here is highly stylized. Each individual possesses a private and untransferable production technology through which their capital can be invested. $^{2}$ This investment is irreversible. The return of each private technology is linear in the capital invested and subject to stochastic shocks. Across time, these shocks are identically and independently distributed (i.i.d.). Meanwhile, across individuals, there may be some dependence on the realization of these shocks, but they are drawn in such a way that there is no aggregate risk and in this sense individual risk is idiosyncratic. ${ }^{3}$ With complete markets, idiosyncratic risk would be eliminated through insurance or through a diversified portfolio. However, the model assumes that individuals' identity, capital, and output are private information and known only by these individuals themselves. Therefore, idiosyncratic risk cannot be diversified away, and capital cannot be used as collateral for loans. Individuals can partly self-insure by holding money. In other words, individuals can sell part of the output they obtained for money after a favorable shock, and use this money to finance their expenditures in the event of a bad shock.

Analyzing individuals' behavior in this environment has an interest of its own as it extends the income fluctuations problem in [9] to a framework where wealth can grow endogenously without bound. This unbounded growth implies that the wealth distribution of individuals does not converge to a stationary distribution, but it becomes increasingly disperse. In general, the lack of a stationary distribution of wealth creates a problem because it precludes a stable aggregation of the individuals' 
behavior necessary to construct a balanced path for the economy. Fortunately, this problem can be solved with the same assumptions that imply the existence of a balanced growth path equilibrium for a single individual; namely, the homogeneity of preferences and the linear homogeneity of technologies. These assumptions, though, bring some technical difficulties in the analysis because neither opportunity sets, utility functions, nor their first derivatives are necessarily bounded, as is normally assumed in standard arguments in the income fluctuations problem. Because of these difficulties, these standard arguments need to be replaced with new arguments suitable to the present context.

In the present model, money improves efficiency by allowing individuals to self-insure. In the absence of money, an equilibrium is inefficient because of the assumption that the idiosyncratic risk to individual investments is uninsurable. Individuals can self-insure with money; that is they can consume above their income when the return to their capital is low. In an equilibrium with a constant money supply, money brings this welfare improvement without any other demand on the government other than its ability to convince individuals that money is and will remain valuable. This ability to provide confidence on money may be linked to the taxing powers of the government, but in equilibrium, with a constant money supply, these powers are not exercised. Unfortunately, with a constant money supply, the rate of return to money approaches the growth rate of output, which falls short of the social return to capital. Hence, there is an opportunity cost of self-insuring with money, and in general individuals will not fully insure themselves. The equilibrium with a constant money supply remains inefficient despite the positive welfare role of money.

In principle, the self-insurance role of money can be enhanced by raising the rate of return to money towards the social rate of return to capital. In the limit, first best efficiency can be achieved if 
these two rates are equalized. This is Friedman's rule on the optimum quantity of money (see [10, 4, 20]. $)^{4}$ However, when this rule is implemented, individuals prefer money to capital facing idiosyncratic uninsurable risk. Hence, in order to implement this rule, the government must effectively own the entire capital stock invested in the private technologies with idiosyncratic risk. Furthermore, this policy is only optimal if the government is able to manage this capital as efficiently as private individuals. In this instance, the monetary system plays the role of a gigantic mutual fund that effectively diversifies idiosyncratic risk. The problem with creating this mutual fund is the extraordinary managing abilities demanded from the government. In the absence of these abilities, Friedman's rule cannot be implemented.

The traditional approach of using taxation to implement Friedman's rule is closely related to the public ownership of the capital invested in private technologies. Both taxes and public ownership are fiscal revenue sources founded on government's entitlement to claim a portion of the output produced in the private sector. With taxation, Friedman's rule can only be implemented with a 100 percent tax on the returns to capital with idiosyncratic risk coupled with a 100 percent subsidy on the investment of this type of capital. As a result, this policy is equivalent to the public ownership of capital with idiosyncratic risk.

The present analysis of the optimum quantity of money complements the work in $[5,13,15,17$, 19] on the difficulties of implementing Friedman's rule when money plays a precautionary role. In all these papers, individuals own a stream of endowments and money is the only asset for transferring purchasing power across periods. Furthermore, the government pays for the money supply reductions with the revenue of a uniform lump-sum tax, or it spends the money supply expansions financing a 
uniform lump-sum subsidy. The revenue from a uniform lump-sum tax is bounded by the minimal income each individual receives each period. Hence, the money supply reductions are also bounded, and Friedman's rule may not be attainable or even approximated. Moreover, the distributional effect of using a uniform lump-sum tax to finance reductions of the money supply is likely to be perverse for welfare. For example, in [17] individuals get net positive transfers when their money balances are high and, on average, their marginal utility of consumption is low. The present analysis differs from this earlier work by considering the case that individuals own capital instead of a stream of endowments. This setup offers the conceptual possibility that the government avoids the uniform lump-sum tax to implement Friedman's rule by purchasing all the capital, managing it efficiently, and using its return to finance reductions of the money supply. The difficulty here is the realism of assuming that the government is capable of performing such a task.

In summary, this paper extends the work of Foley and Hellwig [9] and Bewley [4] by incorporating endogenous incomes, capital accumulation, and growth. In this context, money plays both a risk diversification role and a liquidity role. This extension provides a framework in which to reexamine the difficulties in implementing Friedman's rule on the optimal quantity of money. The main outcome from this analysis is an impossibility result. The government cannot implement a first best efficient allocation with a deflation that equates the return to money to the social return to capital without gaining effective ownership of the capital stock and being able to operate this stock as efficiently as private agents can. Section 2 describes the model. Section 3 analyzes individual behavior. Section 4 constructs a balanced path equilibrium for the economy. Section 5 reexamines the problem of implementing Friedman's rule on the optimal quantity of money. Finally, section 6 discusses 
generalizations to the present model and concludes. An appendix collects all the proofs.

\section{THE MODEL}

Consider an economy populated with a continuum of individuals. In this economy, individuals possess an untransferable production technology through which their capital can be invested. Capital is the unique input used by these technologies. Output is homogeneous and can either be consumed or invested. Investment is irreversible; that is, once a portion of the good is allocated as capital to a particular technology it can neither be consumed nor relocated to a technology belonging to any other individual. All individual production technologies are stochastic and yield constant returns to scale. Stochastic shocks are drawn so that the individual return to capital is risky, whereas it social return is not. Individuals can easily hide their identity, their capital, and the output this capital produces. Consequently, individuals cannot insure the idiosyncratic risk affecting the return to their capital. Likewise, individuals cannot borrow against their capital. Instead, individuals can partly insure themselves by trading the good for money. After a favorable shock, they can sell part of their output for money. Thus, in the event of a bad shock, they can spend this money to finance their expenditures.

The fact that individuals cannot eliminate the variability of the private return to capital is crucial for money to be valued in this model. That is, money would be unnecessary with costless contracts leading to perfectly diversified firms, full insurance, or frictionless equity markets. All these contracts involve credit from individuals with a high return on their technology to individuals with a low return. For moral hazard reasons, the assumption that individuals can hide their identity, their capital, and the output 
this capital produces precludes the viability of these contracts. Thus, this assumption is equivalent to the assumption common to many theoretical monetary models that there is no technology to enforce credit contracts (e.g. [16]). At the cost of complicating the model, one could assume weaker forms of imperfect information leading to a costly enforcement of credit/insurance contracts to preclude the elimination of all idiosyncratic risk. For simplicity, these alternative assumptions are not pursued in this paper.

Each period, individuals allocate their wealth into consumption, capital, and money. The present flow budget constraint is

$$
c_{i}+k_{i}^{\prime}+m_{i}^{\prime}=x_{i}, \text { all } i \in I
$$

where $I=$ set of individuals;

$c_{i}=$ consumption for $i$

$k_{i} \mathrm{~N}=$ capital stock at the beginning of next period owned by $i$;

$m_{i} \mathrm{~N}=$ real money demand by $i$; and

$x_{i}=$ wealth of $i$.

A prime on a variable denotes the value for that variable next period except for $m_{i} \mathrm{Nwhich}$ is the nominal quantity of money carried to the next period divided by this period's price level. In choosing this allocation, consumption, gross investment, and money demand must be nonnegative:

$$
c_{i} \geq 0 ; \quad k_{i}^{\prime}-\mu k_{i} \geq 0 ; \quad m_{i}^{\prime} \geq 0
$$

where $\mu=$ survival rate of capital $(\mu>0)$.

The initial level of wealth $x_{i}$ is positive for all $i$. 
The wealth at the beginning of next period has two components: liquid wealth and surviving capital. In turn, liquid wealth includes the output to be obtained from capital and the real value of money:

$$
\begin{aligned}
& x_{i}^{\prime}=y_{i}^{\prime}+\mu k_{i}^{\prime}, \text { and } \\
& y_{i}^{\prime}=z_{i}^{\prime} k_{i}^{\prime}+\frac{m_{i}^{\prime} p}{p^{\prime}} \equiv z_{i}^{\prime} k_{i}^{\prime}+m_{i}^{\prime}(1+r) .
\end{aligned}
$$

where $y_{i} \mathrm{~N}=$ liquid wealth of $i$ next period;

$z_{i} \mathrm{~N}=$ return to the capital of $i$ next period;

$p=$ price of output; and

$r=(p / p \mathbb{N}-1$ is the (real) return to money.

The realizations of the stochastic shock $z_{i}$ Nare countable, nonnegative, and bounded. The distribution of $z_{i} \mathrm{Nis}$ identical both across time and individuals. For a given individual, $z_{i}$ Nis independent across time, although not necessarily across individuals. For a given period, the cumulative frequency of $z_{i}$ Nacross individuals is the distribution function of $z_{i}$ Nfor a given $i$; that is, there is no aggregate uncertainty. ${ }^{5}$ In addition, for ease of exposition, I will assume that the probabilities of $z_{i}$ Nattaining its lower bound, $z^{\text {Min }}$, and its upper bound, $z^{\operatorname{Max}}\left(z^{\operatorname{Max}}>z^{\operatorname{Min}}\right)$, are strictly positive.

The individuals' horizon is infinite, their preferences are time additive, and their instantaneous utility function is isoelastic. In recursive form, the utility of $i$ is:

$$
V_{i}=\frac{c_{i}^{1-\sigma}}{1-\sigma}+\beta E V_{i}^{\prime}
$$


where $B=$ discount factor $(B>0)$; and

$\mathrm{s}=$ coefficient of relative risk aversion ( $\mathrm{s}>0$, and utility is logarithmic if $\mathrm{s}=1$ ).

Because of its liquidity services, individuals demand money even if its rate of return is stochastically dominated by the rate of return to capital. Without the irreversibility constraint on capital, the demand for money is just a demand for diversifying risk. With the irreversibility constraint, the demand for money is also a demand for liquidity and is likely to be positive for a wide range of parameters. For example, the demand for money is always positive if $z^{\mathrm{Min}}=0$ and the return factor $p / p$ Nremains positive in all states. Therefore, the demand for money is positive even if the money return factor $\left(p / p \mathbb{N}\right.$ is lower than the capital return factor $\left(\mu+z_{i} N\right.$ in all realizations of $z_{i} N$ The two assumptions responsible for this strong result are the following: the marginal utility of consumption converges to infinity as consumption converges to zero and the probability of a zero gross return to capital $\left(z_{i} \mathrm{~N}=0\right)$ is positive. As shown in the next section, the demand for money may exist even if $z^{\text {Min }}$ $>0$ and money is dominated in its the rate of return, but a positive demand is not guaranteed in such general terms.

For the time being, I assume that the money supply is constant. In principle, the money supply may change if the government uses taxes or transfers to change its quantity. This possibility is postponed until Section 5. As long as the nominal quantity of money is constant, the only economic transactions in the economy consist of exchanges of money and output in a market that takes place every period. Using the fact that $z$ is independent of $k$, this market clearing condition can be stated as follows:

$$
C+K^{\prime}-\mu K=\bar{z} K
$$


where uppercase letters represent economy aggregates (i.e., they are integrals of their lowercase analogs across all $i$ in $I$ ), and Gis the expected value of $z_{i}$. Equivalently, the market clears when:

$$
M_{N}=M^{\prime} p
$$

where $M_{N}=$ nominal quantity of money.

This paper studies monetary competitive equilibria where individuals maximize $V_{i}$, taking prices as given, subject to constraints (1) to (3), and where the market that exchanges money and output clears every period. As it is typical among monetary models ${ }^{6}$, these equilibria are not unique. This paper, though, does not deal with this multiplicity. Instead, if focuses on balanced path equilibria consistent with a constant rate of return to money.

\section{INDIVIDUAL BEHAVIOR}

This section characterizes the optimal behavior of an individual facing a constant return to money. The individual's optimal plan must satisfy the following standard first order conditions. ${ }^{7}$ If the demand for money is positive, a marginal unit of output must bring the same utility to an individual whether immediately consumed or sold for $p$ units of money to be spent on consumption next period ( $p$ / $p$ Nunits). If the demand for money is zero, consuming the unit of output immediately gives at least the same utility as selling it for money. These two complementary conditions are summarized as follows:

$$
c^{-\sigma} \geq \beta E \frac{p c^{\prime-\sigma}}{p^{\prime}}, \text { with equality if } m^{\prime}>0 \text {. }
$$


(Henceforth individuals' subscripts are dropped when unnecessary). Also, if the irreversibility constraint on capital is not binding, a marginal unit of output must bring the same utility to an individual whether immediately consumed or invested and the return consumed throughout the life of the irreversible investment. If the irreversibility constraint is strictly binding, the individual would get at least the same utility consuming one unit of capital as he/she would get if left invested because of the constraint. These two complementary conditions are summarized as follows:

$$
c_{0}^{-\sigma} \geq \beta \sum_{t=1}^{\infty}(\beta \mu)^{t-1} E_{0} z_{t} c_{t}^{-\sigma}, \text { with equality if } k_{1}>\mu k_{0} ;
$$

where subscripts denote time and the present is normalized to be period zero. A recursive application of this condition implies the following relation:

$$
\sum_{t=1}^{\infty}(\beta \mu)^{t-1} E_{0} z_{t} c_{t}^{-\sigma} \leq E_{0}\left(z_{1}+\mu\right) c_{1}^{-\sigma} \text {, with equality if } \operatorname{Pr}\left(k_{2}>\mu k_{1}\right)=1 \text {. }
$$

The irreversibility constraint lowers the value of an investment next period unless the constraint is not to be strictly binding with probability one.

To ensure that the individual's problem is properly defined, one must ensure that there is at most one feasible path that yields infinite utility to the individual. Also, one must ensure that there is at least one feasible path for which utility is different from minus infinity. As shown in proposition 3.1 below, the following assumption achieves both objectives.

ASSUMPTION 3.1: Technology and preferences satisfy these additional restrictions:

(i) If $s<1$, then $\beta\left(\mu+z^{\text {Max }}\right)^{1-\sigma}<1$, and $z^{\text {Min }} \$ 0$.

(ii) If $s=1$, then $\beta<1$, and $z^{\text {Min }}>0$. 
An additional assumption on the variability of $z$ Nis also necessary to ensure that the demand for money is positive. As discussed in Section 2, one such assumption is that $z^{\text {Min }}=0$. With this assumption, one cannot ensure that the expected individual's utility is different from minus infinity if $\mathrm{s} \$ 1$. Hence the assumption $z^{\text {Min }}=0$ is unsuitable for this range of $\mathrm{s}$. With a positive $z^{\text {Min }}$, conditions on the primitives of the model that ensure a positive $m$ Nare complicated to state, and they lack generality. Condition 3.1 posits a positive demand for money for a level of liquid wealth of particular interest to ensure a monetary equilibrium. In this case, proposition 3.1 shows that this condition is satisfied for all values of $\mathrm{s}$ if the survival rate is sufficiently high and the distribution of $z$ Nis sufficiently disperse.

CONDITION 3.1: The demand for money $m \mathrm{~N}$ is positive for $k=1$ and $y=z^{\operatorname{Max}}$.

If Assumption 3.1 and Condition 3.1 are satisfied, individuals may find themselves in three possible regimes depending on the constraints binding in a particular period. In regime A, neither the irreversibility constraint nor the nonnegative money demand constraint are binding. In this regime, the allocation of wealth $\left(c, k^{\prime}, m^{\prime}\right)$ is proportional to $x$. In regime $\mathrm{B}$, only the irreversibility constraint is binding. In this regime, gross investment is zero, and a portion of liquid wealth is used to finance consumption. In regime $\mathrm{C}$, both constraints are binding. In this regime, individuals consume all their liquid wealth. For high liquid wealth relative to capital, regime A applies. For lower liquid wealth, regime B applies. Finally, regime $\mathrm{C}$ applies for the lowest interval of liquid wealth. The existence of 
regimes $\mathrm{B}$ and $\mathrm{C}$ depends on parameter values as formalized in the following proposition:

PROPOSITION 3.1: With the restrictions in Assumption 3.1, if $1-\mu \leq r<\bar{z}-(1-\mu)$, the following statements apply to an individual's optimization problem:

(i) Recursive dynamic programing methods are applicable, and the optimal policy is a continuous and linearly homogeneous function of liquid wealth and capital:

$$
\left(c, m \mathbb{N} k \mathrm{~N}=G(y, k) \in R_{+}^{3} \text {. Hence for } k>0, G(y, k)=G(s, 1) k \text {; where } s=y / k\right. \text {. }
$$

(ii) If Condition 3.1 is satisfied, for $k=1$ õ $s^{*}$ and $\diamond\left(s^{*}>\diamond \$ 0\right.$, and $\left.z^{\text {Max }}>\diamond\right)$ such that:
(A) For $\mathrm{O}\left(s^{*}, 4\right) 1\left[z^{\mathrm{Min}}, 4\right)$, the optimal choice is interior and $c$, $m$ Nand $k$ Nare proportional to $x$.

(B) For y $0\left(\emptyset, s^{*}\right] 1\left[z^{\text {Min }}\right.$, 4) (this set could be empty), $k \mathrm{~N}=\mu k, m \mathrm{~N}>0$, and $c$ and $m \mathrm{~N}$ are strictly increasing functions of $y$.

(C) For y $0[0, \nabla] 1\left[z^{M i n}, 4\right)$ (this set could be empty), $k \mathrm{~N}=\mu k, m \mathrm{~N}=0$, and $c=x-\mu k$.

(iii) For all preferences parameters, Condition 3.1 is satisfied if the survival rate is sufficiently high, and the distribution of zNis sufficiently disperse.

The linear homogeneity of $G$ implies that wealth grows stochastically, so that in general the level of wealth does not converge to an invariant distribution. In contrast, the proportion of liquid wealth over capital is bounded, so that an invariant distribution for $s$ (the ratio $y / k$ ) exists. The monotone properties of $G$ imply convergence to this distribution in the long-run. Also, the following lemma provides a "mixing" result that implies uniqueness of this distribution. 
LEMMA 3.1: Let $s^{* *}=(m / k)^{*}(1+r)+z^{\text {Max }}$, where $(m / k)^{*}$ is the ratio $m \mathrm{~N} k \mathrm{~N}$ in Regime $A$ (interior solution). Suppose Assumption 3.1 and Condition 3.1 hold.

(i) If $\beta(1+r) \mu^{-s} \$ 1$, then the probabilities of finite time transitions either from $s_{0}=z^{\text {Min }}$ to $s_{t}=s^{* *}$ or from $s_{0}=s^{* *}$ to $s_{t}=s^{* *}$ are positive. (Subscripts denote periods into the future).

(ii) If $\beta(1+r) \mu^{-s} \# 1$, then the probabilities of finite time transitions either from $s_{0}=z^{\text {Min }}$ to $s_{t} \$ z^{\operatorname{Max}}$ or from $s_{0}=s^{* *}$ to $s_{t} \# z^{\text {Max }}$ are positive.

Proposition 3.2: Let s be the ratio y/k. Suppose Assumption 3.1 and Condition 3.1 hold, and $1-\mu \leq r<\bar{z}-(1-\mu)$. Let $P(s, s \mathrm{~N}$ be the transition function defining the probability distribution of sNgiven s. This transition function has a unique invariant distribution. This distribution assigns positive probability to states with a positive demand for money. The longrun distribution of s converges to this invariant distribution.

This proposition applies to alternative parameter values leading to a broad range of individual behavior. In particular, it applies to parameter values for which positive gross investment never arises in the ergodic set of states. In this case, individuals have an invariant distribution indistinguishable from that of the standard income fluctuations problem with an exogenous growth factor $\mu$. Furthermore, Proposition 3.2 applies to parameter values for which income grows endogenously because the invariant distribution assigns positive probability to states with positive gross investment. 


\section{THE BALANCED PATH EQUILIBRIUM}

This section uses the results of Section 3 to construct a balanced path equilibrium when the money supply is constant. Suppose that individuals in the economy have a relative distribution of liquid wealth and capital so that the contemporaneous cumulative frequency of $s$ (the ratio $y / k$ ) across individuals is the long-run invariant distribution of $s$ for any single individual. Therefore, by definition, the distribution of $s$ across individuals remains invariant over time. This section restricts attention to economies with this invariant distribution of $s$ across individuals. These economies, though, are not necessarily in a balanced path. The allocation of aggregate output depends not only on the distribution of $s$ across individuals but also on the distribution of wealth across individuals. In general, the distribution of wealth across individuals has no invariant distribution in this model because the wealth of each individual grows stochastically and without bound. The lack of a stationary distribution of wealth poses a difficulty for aggregating individual behavior into a stable balanced path for the economy. However, this section shows that this difficulty can be overcome using the linear homogeneity of the individual's policy function.

Let $S=\left[s^{\text {Min }}, s^{\text {Max }}\right]$ be a closure of the ergodic set of states for the individual transition function $P\left(s, s \mathbb{N}\right.$, and let ? $(S)$ be the set of distribution functions on $S$. For all $s 0 S$, let $K^{s}$ be the aggregate capital stock of all individuals having a common $s$. The linear homogeneity of $G$ for all individuals implies that the allocation of aggregate output depends on how aggregate capital is divided among the various $K^{s}$. That is, 


$$
\left(C, M^{\prime}, K^{\prime}\right)=\int_{I} G\left(y_{i}, k_{i}\right)=K \int_{S} G(s, 1)\left(K^{s} / K\right) .
$$

The first equality in (10) is a definition. The second equality in (10) follows from the linear homogeneity of $G$ and the aggregation of all individuals with a common $s$. To construct a balanced path equilibrium, one must find an invariant distribution for $K^{s} / K$. Let ? 0? (S) be the present cumulative frequency of $K^{s} / K$, and let $T^{*}$ be an internal operator in ? (S) that maps ? onto the next period cumulative frequency of $K^{s} / K$. That is,

$$
\left(T^{*} \lambda\right)\left(s^{\prime}\right)=\frac{\int g_{k}(s) P\left(s, s^{\prime}\right) \lambda(d s)}{\int g_{k}(s) \lambda(d s)},
$$

where $g_{k}$ is the third element of $G(s, 1)$. The sought invariant distribution of $K^{s} / K$ is a fixed point ?* of the operator $T^{*}$. By comparison, the long-run invariant distribution of $s$ for an individual is the fixed point $?_{i}^{*}$ of the operator

$$
\left(T_{i}^{*} \lambda_{i}\right)\left(s^{\prime}\right)=\int P\left(s, s^{\prime}\right) \lambda_{i}(d s) .
$$

The two fixed points would be identical if $s \mathrm{~N}_{w}$ ere independent of $s$ ( $P$ could be taken out of the integrals in (11) and (12)), or if $g_{k}$ were a constant ( $g_{k}$ could be taken out of the integrals in (11)). In general, the two fixed points differ because the transition function $P$ is monotone with $s$, and $g_{k}$ is increasing (strictly for some states). The following proposition establishes the properties of $T^{*}$ and the convergence of the cumulative frequency of $K^{s} / K$ to a unique invariant distribution ?*.

PROPOSITION 4.1: Suppose Assumption 3.1 and Condition 3.1 hold, and 
$1-\mu \leq r<\bar{z}-(1-\mu)$. The operator $T^{*}$ satisfies the following properties:

(i) Continuity: For a sequence $?_{n}$ of elements in ?(S), $T^{*} ?_{n}$ converges weakly to $T^{*} ?$ if $?_{n} 6$ ?.

(ii) Monotonicity: For $?_{1}, ?_{2} 0 ?(S), T^{*} ?_{1} \$ T^{*} ?_{2}$ if $?_{1} \$ ?_{2}$.

(iii) Dominance: For all ? 0? $(S), T_{i}^{*} ? \$ T^{*} ? \$ P\left(s^{*}\right.$, @. Moreover, $T_{i}^{*} ?=T^{*} ?$ if $?\left(s^{*}\right)=1$ or $?(s)=0$ for all $s<s^{*}$.

(iv) Invariant Distribution: The cumulative frequency of $K^{s} / K$ converges to a unique invariant distribution ?* of the $T^{*}$ mapping.

If the cumulative frequencies of individuals and capital correspond with the invariant distributions $?_{i}^{*}$ and $?^{*}$, the aggregate allocation of resources in the economy will remain constant over time. Therefore, the aggregate of all real variables in the economy (wealth, consumption, capital, output, and real money balances) will grow at a constant common rate $g$. For this balanced path to be an equilibrium, one must ensure that the market of output for money clears. The following proposition establishes that there is an $r$ that achieves this outcome.

PROPOSITION 4.2: Suppose Assumption 3.1 and Condition 3.1 hold. There is a real return to money $r$ in the range $1-\mu \leq r<\bar{z}-(1-\mu)$ for which the market of output for money clears along an aggregate balanced path. Consequently, a monetary balanced path equilibrium exists.

The balanced path equilibrium constructed in this section is not Pareto efficient. For efficiency, 
individuals should be able to earn the social return to capital $\bar{z}-(1-\mu)$ on all their investments including money. The next section examines the policies required to achieve this end.

\section{THE OPTIMUM QUANTITY OF MONEY}

This section analyzes policies aimed to remedy the inefficiency caused by the gap between the return to money and the social return to capital. To narrow this gap the government can pay interest on money or change the rate of deflation. As these policies are equivalent in this model, I will assume no interest is paid on money. In this case, the Friedman's rule to achieve first best efficiency calls for a rate of deflation equal to the social return to capital. With the simplifications made, the social return to capital is constant along a balanced path, so that there is no need for risk adjustments. (This absence of aggregate risk is not essential to the main results presented below.)

With a constant money supply, the rate of deflation falls short of the social return to capital meaning that a government seeking to implement Friedman's rule must steadily reduce the money supply. I will assume that the government uses a combination of lump-sum taxes and income from publicly owned capital to finance these reductions of the money supply. Thus, in this section, I assume that the government is able to invest in capital to obtain a constant real net return $r_{g}$. This ability can be interpreted in two ways, both yielding identical results. One interpretation is that the government owns a technology different from private technologies in which it can invest the capital it owns. The other interpretation, more in tune with the rest of the paper, is that the government can invest in the private technologies to obtain an aggregate return without risk. This return may differ from the average return of 
private investments (social return to capital) because of possible costs or inefficiencies when the government uses the private technologies.

The next proposition examines the implications of closing the gap between the return to money and the social return to capital in a balanced path equilibrium. These implications put a set of conditions on what the government must be able to do to implement Friedman's rule on the optimum quantity of money to improve efficiency.

PROPOSITION 5.1: In a balanced path where $r=\bar{z}-(1-\mu)$, the following holds:

(i) The government must own all the capital stock.

(ii) The money supply must be backed with the present value of the net cash flow from public capital plus the present value of future taxes.

(iii) If the public return to capital is lower than the social return to capital: $r_{g}<\bar{z}-(1-\mu)$, and non redistributive lump-sum taxes subsidize the monetary system to achieve $r=\bar{z}-(1-\mu)$, then eliminating taxes and lowering the return to money to $r_{g}$ is a Pareto improvement.

Proposition 5.1 implies that Friedman's rule leads to a prescription for using the fiscal powers to create a mutual fund where the government owns all the capital and distributes its proceeds through the monetary system. ${ }^{8}$ For this scheme to be efficient, public capital must be able to earn the social return to capital. Therefore, the government must either have a technology with the same expected return as private technologies but without risk, or be able to invest in the private technologies without the 
monitoring costs that prevent private individuals from doing so. Because the only market imperfection in this economy is the impossibility of individuals to fully diversify risk, it is clear that if the government can create this public mutual fund efficiency will be improved. The point of Proposition 5.1, though, is not this "if" statement. The point of the proposition is that only if the government can create this public mutual fund, then Friedman's rule can be implemented to improve efficiency. The intuition for this is simple. Once the return to money is equal to the expected return to capital, risk averse individuals prefer money to capital facing an idiosyncratic uninsurable risk. Hence all the capital with idiosyncratic risk must be owned by the government in a balanced growth path. This policy is only optimal if the government can manage capital as efficiently as private individuals.

The realism of the capabilities demanded from the government in Proposition 5.1 is ultimately an empirical matter. However, the conventional wisdom is that governments are worse administrators of their capital than the private sector. Hence, Proposition 5.1 should be seen as an impossibility result. Friedman's rule cannot be implemented to improve efficiency if either the ownership of capital must be private or the return to public capital falls short of the social return to capital.

As in [5], Proposition 5.1 implies that if the government must rely only on lump-sum taxes to finance the reductions of the money supply, Friedman's rule cannot be achieved. Suppose, as in [5], that the only fiscal instrument the government possesses is a lump-sum tax uniform across individuals. With a lump-sum tax the first order conditions (7) and (9) of the individuals' optimal plans are not affected, but their budget constraint is. Also, when a lump-sum tax is used to reduce the supply of money, it affects the equilibrium condition (6), and as a result, changes the rate of deflation in the economy. For the tax to be able to support a steady deflation, the tax revenue must grow at the same 
rate as the economy. The characterization of a balanced path equilibrium follows similar steps to those in Section 4. This characterization now implies that the return to money equals the rate of growth of the economy minus the rate at which the money supply is reduced. This equilibrium, though, only exists if the uniform lump-sum tax is sufficiently small so that all individuals are able to pay it. In this model (and in reality!), this puts a very low bound on the tax. In this model, even if the economy settles into a balanced path with a constant rate of growth for aggregate variables, as long as idiosyncratic risk is not eliminated, the individuals' wealth distribution is increasingly disperse. Therefore, even if we were to start with an equal distribution of wealth, the wealth of some individuals will become insignificant relative to that of others. In fact, if the survival rate is less than one $(\mu<1)$ and the investment irreversibility constraint is binding for some individuals along the balanced path, then the wealth of some individuals drifts to zero with probability one. Therefore, in this case, even if the gross rate of return to capital is positive $\left(z^{\operatorname{Min}}>0\right)$, gross income drifts to zero, and so an equilibrium fails to exists for any positive uniform lump-sum tax.

Lump-sum taxes do not need to be uniform across individuals. In the present model, a consumption tax at a constant rate is equivalent to a lump-sum tax proportional to wealth. This consumption tax transfers a portion of wealth, which includes private capital, money, and income, to the government. As the tax rate on consumption increases, private risk becomes diversified because both the value of private capital and its uninsured return falls in consumption units. Nevertheless, there is no finite tax rate that is capable of reducing private risk to zero. This difficulty rules out Friedman's rule, but it does not rule out a close approximation. There are, however, other difficulties with a consumption tax (and, in general, with other taxes that discriminate across individuals as discussed in [15]). To 
approximate Friedman's rule, consumption taxes must be extremely high and collected at a zero monitoring cost. For example, the government must be able to costlessly enforce a system in which $\$ 99.99$ of every $\$ 100$ paid by buyers goes to taxes while the remaining $\$ 0.01$ goes to the seller. In addition, for the tax to be efficient the government must be able to perfectly measure consumption. This assumption is very strong both in reality and in a model where individuals can hide their economic activities. If the government can only measure consumption with error, a scheme which taxes consumption and subsidizes money in order to promote social insurance may easily increase the risk faced by private individuals. The second best monetary policy in this case depends on the relative variability of the measurement error on consumption and the private return to capital. This second best may be far from the Friedman's rule.

\section{SUMMARY AND EXTENSIONS}

This paper has analyzed a simple model where money plays a risk diversification role that partly insulates consumption from the uninsurable idiosyncratic risks, and a liquidity role that relaxes the constraints imposed by investment irreversibility. This model provides intuitive results on the difficulties for engineering a deflation that equates the rate of return to money to the social rate of return to capital (Friedman's rule on the optimal quantity of money). The implementation of this rule converts the monetary system into a huge mutual fund whose assets are the capital with idiosyncratic risk and whose liabilities are the money supply. For this rule to be efficient, the government must be as able to efficiently operate capital as private individuals. If this is not possible, or if the ownership of capital must be private, the return to money cannot be equated to the social return to capital. 
The simplifying assumptions about the private technology and the stochastic environment throughout the paper were done mainly to facilitate the description of the balanced path equilibrium. This section briefly describes some extensions to the basic model, and how they affect the analysis of the optimum quantity of money.

The assumption that investment is irreversible plays a role in ensuring a positive demand for money. If capital is a flexible asset, the money's only role is to diversify individual risk. That is, money is demanded by risk averse individuals that are willing to sacrifice in the margin the high expected return to capital for the safe return to money. In this case, a positive demand for money exists only when the rate of return to money is sufficiently close to the expected social rate of return to capital. This existence problem, though, is not an issue for economies where these two rates are very close as it is the case for economies following or close to following Friedman's rule.

The absence of aggregate risk can also be easily relaxed. With aggregate risk, first best efficiency still calls for eliminating the gap between the return to money and the social return to capital. Hence the return to money must be risky. Arguments parallel to those in Proposition 5.1 imply that this first best can be achieved if and only if all capital is publicly owned and the public return to capital is equal to the social return to capital. The reductions of the money supply must now depend on the stochastic social return to capital which provides the funds to equate the return to money to the social return to capital.

The motives for holding money can also be easily enlarged. With shocks to private technologies that are not i.i.d. across time, the demand for money incorporates both a transaction motive and a speculative motive. For example, suppose individuals obtain the output from their production 
technology once every thirty periods with different individuals receiving their output at different times. The return to capital on the thirtieth day is still stochastic but has a low variance. In this variation of the model, the main motive for holding money is to buy consumption during the twenty-nine periods without income. Thus, it incorporates a typical transaction demand for money. Another example, suppose the productivity of the private production technologies can be imperfectly predicted at the moment investment takes place. In this variation of the model, an additional motive for holding money is to concentrate investment in periods with good prospects on the private return to capital. Thus, this variation would incorporate a speculative demand for money. Although these variations complicate the description of a long-run equilibrium, they add little to the results on the optimum quantity of money in Section 5. The only key assumption in Proposition 5.1 is that the private return to capital contains an idiosyncratic component, which due to market imperfections cannot be insured.

Both the idiosyncrasy on the return to capital and the complete irreversibility of investment could be relaxed with transaction costs to trade physical capital and idiosyncratic shocks to the ability to supply human capital as in $[1] .{ }^{9}$ For similar reasons as elicited in Section 5, the return to money cannot be raised to equal the social return to capital without the government owning all the physical as well as human capital. In this case, the uninsurable idiosyncratic risk of owning physical capital is the transactions expenses that must be incurred to sell out this capital when a bad shock hits an individual.

Finally, the model can be extended to enrich the financial sector in the economy. First, the model can be extended to include several types of government securities differentiated by their liquidity and their rate of return. Highly liquid securities with a low return can then be interpreted as moneys, while less liquid securities with a higher return can be interpreted as government debt. In a separate 
paper [7], I pursue this extension in a deterministic version of the model. Second, the model can be extended to include financial markets and private financial intermediaries. ${ }^{10}$ For example, one could assume that private financial intermediaries could pool idiosyncratic risk and provide credit at a positive resource cost. In such a world, the government issued currency would coexist with the liabilities issued by the private financial intermediaries in a way similar to the coexistence of currency, deposits, and mutual funds in the United States. Monetary policies must then be integrated into the wider overall design and regulation of the financial system. 


\section{APPENDIX A. PROOF OF THEOREMS}

The proofs that follow are abbreviated because they are mainly based on standard dynamic programming arguments. See [6, Appendix B] for a more detailed version of these proofs.

Proof OF Proposition 3.1: Part (i) follows from the theorems in [2]. To apply these theorems for $\mathrm{s} \$ 1$, the ratio $c / x$ must be bounded away from zero. It is possible to construct this bound so it never binds, because for s $\$ 1 y / x \$ z^{\operatorname{Min}}>0$.

The four possible regimes for the solution to the individual's problem are:

(A) The solution is interior. In this regime, $y$ and $\mu k$ are perfect substitutes, so the linear homogeneity of $G$ implies that $c, m$ Nand $k$ Nare proportional to $x$.

(B) Only the irreversibility constraint is binding $(k N=\mu k)$. Homogeneous preferences imply normality of $c$ at all periods and states, so $c$ and $m$ Nare strictly increasing with $y$.

(C) Both constraints are binding $(k N=\mu k$, and $m \mathrm{~N}=0)$. Hence $c=z k+m(1+r)$.

(D) Only the nonnegative money demand constraint is binding $(m \mathrm{~N}=0)$. As in the regime A, $y$ and $\mu k$ are perfect substitutes, so $c$ and $k$ Nare proportional to $x$.

For $k=1$, the demands for $k$ Nand $m$ Nare weakly increasing with respect to $y$, so lower bound constraints on these choices if they bind, they must do so for low levels of $y$. Also, when the irreversibility constraint is not binding the demands for $k$ Nand $m$ Nare proportional to $x$. These two facts imply the following two ordering conditions. If regime $\mathrm{C}$ exists, it must be for the lowest interval of $y:\left[z^{\operatorname{Min}}, \backslash\right]$. If regimes A or D exist, it must be for the highest interval of $y:\left(s^{*}, 4\right)$. Hence regimes A and 
D are mutually exclusive. Regime $\mathrm{D}$ is also mutually exclusive with regime $\mathrm{B}$, because otherwise the demands for either $k$ Nor $m$ Nwould not be weakly increasing with $y$. As a result, Condition 3.1 rules out the existence of the regime D. Combining these ordering conditions with the continuity of $G$ part (ii) follows. This proves (ii).

$$
\begin{gathered}
\text { Let } k=1 \text { and } z^{\operatorname{Min}}<\operatorname{Min}\left\{z_{1}, z_{2}, z_{3}\right\} \text {; where } z_{1}=\mu\left(\left[\beta E\left(\mu+z^{\prime}\right)^{1-\sigma}\right]^{\frac{-1}{\sigma}}-1\right) \text {, } \\
z_{2}=z^{\operatorname{Max}}\left[\operatorname{Pr}\left(z^{M i n}\right) \beta \mu^{1-\sigma}\right]^{1 / \sigma} \text {, and } z_{3}=\mu\left(1-\beta \mu^{1-\sigma}\right)-E\left(z^{\prime} \mid z^{\prime} \neq z^{M i n}\right)\left[\operatorname{Pr}\left(z^{M i n}\right)^{-1}-1\right] \text {. The }
\end{gathered}
$$

inequality $z^{\operatorname{Min}}<\operatorname{Min}\left\{z_{1}, z_{2}, z_{3}\right\}$ rules out the three possible cases which can arise when $m \mathrm{~N}=0$ at $y=$ $z^{M a x}$. These three possible cases are the following: First, $k \mathrm{~N}>\mu$ both at $y=z^{\operatorname{Max}}$ and $y=z^{\operatorname{Min}}$. In this case, $m \aleph=0$ and $k \aleph \triangleright \mu$ for all $y$. Second, $k N=\mu$ at $y=z^{M a x}$. In this case, $m N=0$ and $k N=\mu$ at $y=z^{\text {Min }}$ as well. And third, $k \aleph \triangleright \mu$ at $y=z^{\text {Max }}$, but $k N=\mu$ at $y=z^{\text {Min }}$. Condition $z^{\text {Min }}<z_{1}$ rules out the first case as it contradicts that conditions (8) and (9) hold always with equality. Condition $z^{\text {Min }}<z_{2}$ rules out the second case as it contradicts condition (7). Finally, the condition $z^{\text {Min }}<z_{3}$ rules out the third case as it contradicts that the individual cannot raise utility by a marginal shift of savings from investment to money (conditions (7) to (9))

ProOF OF LEMMA 3.1: If $s \$ s^{*}$ and $z N=z^{\operatorname{Max}}$, the definition of $s^{* *}$ implies $s N=s^{* *}$. If $z^{\operatorname{Max}} \$ s^{*}$, a realization $z \mathrm{~N}=z^{M a x}$ always leads to $s \mathrm{~N} s^{* *}$. Therefore, in this case the probability of a transition from $s_{0}=z^{\operatorname{Min}}$ to $s_{2} \$ s^{* *}$ in two periods is at least $\left[\operatorname{Pr}\left(z^{\operatorname{Max}}\right)\right]^{2}>0$. If $z^{\operatorname{Max}}<s^{*}$, Proposition 3.1 implies that $k \mathrm{~N}=\mu k$, and $m \mathrm{~N} \gg 0$, for all $s 0\left[z^{\operatorname{Max}}, s^{*}\right]$. Also, this proposition implies that $c=g_{c}(s) k$ for a continuous and increasing function $g_{c}$. Thus, for all $s 0\left[z^{M a x}, s^{*}\right]$ condition (7) implies $g_{c}\left(s N>g_{c}(s)\right.$ and $s \bowtie s$ for all $s 0\left[z^{\operatorname{Max}}, s^{*}\right]$ if $z \mathrm{~N}=z^{\operatorname{Max}}$ and $\mathrm{B}(1+r) \mu^{-s} \$ 1$. Let ? be the minimum $s \mathrm{~N}-s>0$ for all $s$ in the compact 
set $\left[z^{\operatorname{Max}}, s^{*}\right]$. For a consecutive sequence of $z N=z^{\operatorname{Max}}$ a transition from $s_{0}=z^{\operatorname{Min}}$ to $s_{N} \$ s^{* *}$ takes at most $N=\left[\left(s^{*}-z^{M a x}\right) / ?\right]+2$ periods. Therefore, the probability of a transition from $s_{0}=z^{\text {Min }}$ to $s_{t} \$$ $s^{* *}$ in finite time is at least $\left[\operatorname{Pr}\left(z^{\operatorname{Max}}\right)\right]^{N}>0$. Finally, $s^{* *}>s^{*}$, because $s \bowtie s$ for $z N=z^{\operatorname{Max}}$ and $y=s^{*}$. Therefore, the probability of a transition from $s^{* *}$ to $s^{* *}$ in a single period is $\operatorname{Pr}\left(z^{\operatorname{Max}}\right)>0$. The proof of (ii) is analogous to the proof of (i) reversing inequalities and considering a sequence of realizations $z \mathrm{~N}=z^{\operatorname{Min}} \sim \sim$

ProOF OF PROPOSITION 3.2: This proposition follows from [18, Theorem 12.12]. Proposition 3.1 implies that $s$ NO $S=\left[z^{M i n}, s^{* *}\right]$ for $s^{* *}$ as defined in Lemma 3.1. The transition function $P$ is clearly monotone and satisfies the Feller property. Lemma 3.1 provides the mixing condition required for the theorem. Finally, Condition 3.1 implies that the set of states with zero money balances is not absorbent $\sim$

ProOF OF Proposition 4.1: Continuity in (i) follows from(11) and $\int_{S} g_{k}(s) \lambda(d s) \geq \mu>0$. Define $S_{\mathrm{o}}=\left[s^{M i n}, s^{*}\right) 1 S$. For all $s 0 S_{\mathrm{o}}, g_{k}(s)=\mu$. Conversely, for all $s 0\left(S-S_{\mathrm{o}}\right), P(s, s \mathbb{\mathbb { N }}=$ $P\left(s^{*}, s N\right)$. Consequently, the definition of $T^{*}$ can be simplified as follows:

$$
\left(T^{*} \lambda\right)\left(s^{\prime}\right)=P\left(s^{*}, s^{\prime}\right)+\mu \kappa^{-1} \int_{S_{0}}\left[P\left(s, s^{\prime}\right)-P\left(s^{*}, s^{\prime}\right)\right] \lambda(d s) ;
$$

where $\mathrm{K}=\int_{S} g_{k}(s) \lambda(d s)$. Because $g_{k}$ is nondecreasing, $?_{1} \# ?_{2}$ if $?_{1} \$ ?_{2}\left(?_{2}\right.$ stochastically dominates $\left.?_{1}\right)$. Likewise, because $P\left(@ s N\right.$ is nonincreasing, the integral in (13) is at least as large for ? ${ }_{1}$ than for $?_{2}$. This proves (ii). 
Using (13) and $P(s, s N)=P\left(s^{*}, s N\right)$ for all $s 0\left(S-S_{0}\right)$,

$$
\left(T^{*} \lambda\right)\left(s^{\prime}\right)=\left(1-\mu \kappa^{-1}\right) P\left(s^{*}, s^{\prime}\right)+\mu \kappa^{-1}\left(T_{i}^{*} \lambda\right)\left(s^{\prime}\right) .
$$

The term $\mu ?^{-1} 0(0,1]$, so (14) implies $T_{i}^{*}$ ? \$ $T^{*}$ ? $\$ P\left(s^{*}\right.$, @. If ? $\left(s^{*}\right)=1$, then the irreversibility constraint is binding with probability 1 in ?. Consequently, $\mu ?^{-1}=1$ and $T_{i}^{*} ?=T^{*}$ ?. Finally, if $?(s)=0$, the irreversibility constraint is strictly binding with zero probability in ?. Consequently, $P\left(s^{*}, @=T_{i}^{*}\right.$ ? = $T^{*}$ ?. This proves (iii).

Form the sequences $\left\{T^{* n} \mathrm{~d}\left(s^{M i n}\right)\right\}$ and $\left\{T^{* n} \mathrm{~d}\left(s^{* *}\right)\right\}$, where $\mathrm{d}(s)$ is a distribution function that assigns unit probability to $s$. Both sequences converge weakly, and their limits $?_{1}^{*}$ and $?_{2}^{*}$ are invariant distributions because $T^{*}$ is continuous and monotone [18, Exercise 12.12]). For all $?_{0} 0 ?(S)$, $\mathrm{d}\left(s^{\operatorname{Min}}\right) \$ ?_{0} \$ \mathrm{~d}\left(s^{\operatorname{Max}}\right)$. Therefore, the monotone property of $T^{*}$ implies:

$$
T^{* n} \mathrm{~d}\left(s^{M i n}\right) \$ T^{* n} ?_{0} \$ T^{* n} \mathrm{~d}\left(s^{\operatorname{Max}}\right), \quad n=1,2, \ldots, \text { all all } ?_{0} 0 ?(S) .
$$

If $?^{*}{ }_{1}=?^{*}$, then it follows that the sequence $\left\{T^{*}{ }^{*}{ }_{0}\right\}$ also converges weakly to this common limiting distribution, and this common limit assigns positive probability to high monetary states because of (iii). Hence, in order to prove (iv) it suffices to prove $?^{*}{ }_{1}=?^{*}{ }_{2}$. Define $S_{\mathrm{o}}=\left[s^{\operatorname{Min}}, s^{*}\right) 1 S$ (the irreversibility constraint is strictly binding at $S_{\mathrm{o}}$ ). Suppose the following condition is satisfied:

(15) There is a positive real e and a positive integer $N$ such that $P^{N}\left(s^{\operatorname{Min}}, s^{*}\right)<1$ - e.

Clearly, this condition implies $s^{*}<s^{\operatorname{Max}}$ and $?_{i}^{*}\left(s^{*}\right)<1$. Moreover, part (iii) implies $T^{* n} \mathrm{~d}\left(s^{M i n}\right)\left(s^{*}\right) \# T_{i}^{* n} \mathrm{~d}\left(s^{M i n}\right)\left(s^{*}\right)$, so $?_{1}{ }^{*}\left(s^{*}\right) \# ?_{i}^{*}\left(s^{*}\right)<1$ by continuity. Because $?^{*}{ }_{1}$ and $?^{*}{ }_{2}$ are finite measures, there is a triple of measures $\mathrm{a}_{0}, \mathrm{a}_{1}$, and $\mathrm{a}_{2}$ such that $?^{*}{ }_{1}=\mathrm{a}_{0}+\mathrm{a}_{1}, ?^{*}{ }_{2}=\mathrm{a}_{0}+\mathrm{a}_{2}$, and $\mathrm{a}_{1}$ 
and $\mathrm{a}_{2}$ are mutually singular. For all $s \mathrm{NO}$, the following expression holds:

$$
\begin{aligned}
\mid \lambda_{1}^{*}\left(s^{\prime}\right)- & \lambda_{2}^{*}\left(s^{\prime}\right) \mid \\
& =T^{*} \lambda_{1}^{*}\left(s^{\prime}\right)-T^{*} \lambda_{2}^{*}\left(s^{\prime}\right) \\
& =\mu \kappa_{1}^{-1} \int_{S_{0}}\left[P\left(s, s^{\prime}\right)-P\left(s^{*}, s^{\prime}\right)\right] \lambda_{1}^{*}(d s)-\mu \kappa_{2}^{-1} \int_{S_{0}}\left[P\left(s, s^{\prime}\right)-P\left(s^{*}, s^{\prime}\right)\right] \lambda_{2}^{*}(d s) \\
& =\mu \kappa_{1}^{-1} \int_{S_{0}}\left[P\left(s, s^{\prime}\right)-P\left(s^{*}, s^{\prime}\right)\right] \alpha_{1}^{*}(d s)-\mu \kappa_{2}^{-1} \int_{S_{0}}\left[P\left(s, s^{\prime}\right)-P\left(s^{*}, s^{\prime}\right)\right] \alpha_{2}^{*}(d s) \\
& \leq \mu \kappa_{1}^{-1}\left[P\left(s^{M i n}, s^{\prime}\right)-P\left(s^{*}, s^{\prime}\right)\right] \int_{S_{0}} \alpha_{1}^{*}(d s) \\
& \leq \mu \kappa_{1}^{-1}\left\|\lambda_{1}^{*}-\lambda_{2}^{*}\right\| .
\end{aligned}
$$

In this expression, the second line uses $?_{1}{ }^{*}$ and $?_{2}{ }^{*}$ are invariant distributions with $T^{*}, ?_{1}{ }^{*} \$ ?_{2}{ }^{*}$, and $T^{*}$ is monotone. The third line uses (13). The fourth line uses that $\mathrm{a}_{0}$ is common to both $?_{1}{ }^{*}$ and $?_{2}{ }^{*}$. The fifth line uses $P\left(s^{M i n}, s \bigvee \mathbb{N} \$ P\left(s, s \mathbb{N} \$ P\left(s^{*}, s \mathbb{N}\right.\right.\right.$ for all $s$ and $s$ Nin $S_{0}$. The sixth line uses $\left[P\left(s^{M i n}, s \mathbb{N}\right.\right.$ $P\left(s^{*}, s \mathrm{~N}\right] \mathrm{0}[0,1]$, and the definitions of $\mathrm{a}_{1}$ and 2@ Because $?_{1}>\mu$ expression (16) implies $2 ?_{1}{ }^{*}-?_{2}{ }^{*} 2=$ 0 , so $?_{1}{ }^{*}=?_{2}{ }^{*}$. This proves uniqueness if (15) holds. If (15) does not hold, $s^{*} \$ s^{\text {Max }}$ and $S=S_{0}$. Hence $T^{*}$ and $T_{i}^{*}$ are identical from (iii), so $?_{\mathrm{i}}{ }^{*}=?_{1}{ }^{*}=?_{2}{ }^{*} \sim$

PROOF OF PROPOSITION 4.2: Individual behavior changes continuously with $r$, so [18, Theorem 12.13] implies that the invariant distributions are also continuous with $r$. The market clearing condition (7) is satisfied if $r=g$. Hence it suffices to prove that there is a pair $r_{1}$ and $r_{2}$ in the range $[1-\mu, \bar{z}-(1-\mu))$ for which $r_{1} \# g_{1}$, and $r_{2} \$ g_{2}$. The inequality $r_{1} \# g_{1}$ is clearly satisfied for $r_{1}=1-\mu$, because the rate of growth of capital is bounded below by $\mu$. For $r_{3}=\bar{z}-(1-\mu)$, individuals do not hold any capital (Proposition 5.1) and do not face risk, so that the wealth grows at the rate $g_{3}=\left[\beta\left(1+r_{3}\right)\right]^{1 / \sigma}-1$. Assumption 3.1 implies $g_{3}<r_{3}$. Continuity of the set of feasible 
consumption paths with respect to $r$ at $r_{3}$ implies the existence of $r_{2}<\bar{z}-(1-\mu)$ sufficiently close to $r_{3}$ for which $g_{2}<r_{2} \sim$

ProOF OF PROPOSITION 5.1: Suppose an individual invests in capital. Condition (8) should hold with equality, so together with (7) to (9) implies

$$
(1+r) E c_{i}^{\prime-\sigma} \leq E\left(z_{i}^{\prime}+\mu\right) c_{i}^{\prime-\sigma}=E\left(z_{i}^{\prime}+\mu\right) E c_{i}^{\prime-\sigma}+\operatorname{Cov}\left(z_{i}^{\prime}, c_{i}^{\prime-\sigma}\right) .
$$

The normality implies the covariance term is negative. Consequently, as long as private gross investment is positive, $r<\bar{z}-(1-\mu)$. Hence if $r=\bar{z}-(1-\mu)$ private investment must be zero, and in a balanced path equilibrium private capital must be zero as well. This proves (i).

Suppose the government reduces the money supply with the proceeds from taxes and the return of public capital. The government's flow budget is $\left(K_{g}^{\prime}-K_{g}\right)+\left(\frac{M_{N}-M_{N}^{\prime}}{p}\right)=K_{g} r_{g}+T_{g}$; where $K_{g}$ $=$ public capital, and $T_{g}=$ current real taxes collected by the government. Along a balanced path equilibrium with $r=\bar{z}-(1-\mu)$ and grow rate $g$, this budget constraint simplifies to $M(r-g)=K_{g}\left(r_{g}-g\right)+T_{g}$. Dividing by $r-g, \quad M=K_{g} \frac{r_{g}-g}{r-g}+\frac{T_{g}}{r-g}$. Consequently, the money supply is backed with the present value of the net cash flow from public capital plus the present value of future taxes, both discounted at the rate $r$. This proves (ii).

As part (i) shows, in a balanced path where $r=\bar{z}-(1-\mu)$ all capital is publicly owned, so the effective return to capital along this balanced path is $r_{g}$. As part (ii) implies, money can only earn a higher return than $r_{g}$ if the government collects lump-sum taxes to subsidize the monetary system. This policy is inefficient as it leads to a disparity between the marginal rates of substitution and transformation 
between present and future output. Furthermore, if the lump-sum taxes are non redistributive (proportional to wealth), a Pareto improvement can be achieved with a monetary reform that cancels taxes and maintains money fully backed with public capital 


\section{APPENDIX B}

This appendix contains more detailed versions of the proofs than those in Appendix A.

ProOf OF Proposition 3.1: The proof of (i) is based on Theorems 1 to 6 in Alvarez and Stokey (1998) extended to a stochastic setting as explained in Section 5 of the same article. Using wealth as the norm for the nonnegative state variables $y$ and $k$, the assumptions of these theorems are clearly satisfied for $\mathrm{s}<1$. For $\mathrm{s} \$ 1$, they are also satisfied with the added constraint $c \$$ a $x$, for all a $\mathrm{O}\left(0, z^{\mathrm{Min}}\right)$. Therefore, recursive arguments can be applied to this problem (once transformed if $\mathrm{s} \$ 1)$, and there is a policy correspondence $G(y, k)$ that is nonempty, compact-valued, upper-hemicontinuous, and linearly homogenenous. The strict concavity of the utility function and convexity of the budget constraint imply that the value function $V$ is strictly concave with respect to $(y, k)$. Hence the maximum utility is attained at a single point of the budget constraint, so $G$ is a single-valued function. Then, the continuity of $G$ is implied by the fact that it is upper-hemi-continuous. Finally, it remains to show that when s $\$ 1$ there is a positive a for which the constraint $c \$$ ax will never be binding, so these results apply to the problem without this constraint. For $x=1$, the minimum liquid wealth, to be denoted $y^{\text {Min }}$, is $z^{\text {Min }} /\left(z^{\text {Min }}+\mu\right)>0$. Let $c^{\text {Min }}=\left[1-\beta^{\frac{1}{\sigma}}\left(\mu+z^{\text {Min }}\right)^{\frac{1}{\sigma}-1}\right] y^{\text {Min }}$. As it is well known, $c^{M i n}$ is the deterministic optimal consumption for an individual with $x=y^{M i n}, z \mathrm{~N}=z^{\text {Min }}$ for all states, and $r=\mu-1$. Assumption 3.1 implies $c^{\text {Min }}>0$. With the homogeneous assumptions of preferences and technology, if the constraint $c \$$ a $x$ is never binding, then $c=\left[\frac{y+q \mu k}{(1-\sigma) V}\right]^{\frac{1}{\sigma}}$ if $\mathrm{s}>1$, and 
$c=(y+q \mu k)(1-\beta)$ if $\mathrm{s}=1$; where $q$ is the shadow value of one unit of inherited capital

(0 \# $q \# 1$ ). (For the derivation, see Faig "Understanding Investment Irreversibility in General Equilibrium" Working Paper FAIG 9801, Department of Economics, University of Toronto. This rule corresponds to equation (14) with different notation). This rule implies that if s $\$ 1$, consumption is weakly increasing with $V$ and $y+q \mu k$. Therefore, if a $<c^{\text {Min }}$, the constraint $c \$$ a $x$ will never be binding. This proves (i).

The two inequality constraints ( $k N \$ \mu k$, and $m N \$ 0$ ) determine four possible regimes for the solution to the individual's optimization problem:

(A) The solution is interior. In this regime, $y$ and $\mu k$ are perfect substitutes, so the linear homogeneity of $G$ implies that $c, m$ Nand $k$ Nare proportional to $x$.

(B) Only the irreversibility constraint is binding $(k N=\mu k)$. In this regime, homogeneous preferences imply normality of consumption at all periods and states, so $c$ and $m$ Nare continuous and strictly increasing functions of $y$.

(C) Both constraints are binding $(k N=\mu k$, and $m \mathrm{~N}=0)$. In this regime, $c=z k+m(1+r)$.

(D) Only the nonnegative money demand constraint is binding $(m N=0)$. In this regime, $y$ and $\mu k$ are perfect substitutes, so the linear homogeneity of $G$ implies that $c$ and $k$ Nare proportional to $x$.

For $k=1$, the demands for $k$ Nand $m$ Nare weakly increasing with respect to $y$, so lower bound constraints on these choices if they bind, they must do so for low levels of $y$. Moreover, when the irreversibility constraint is not binding the demands for $k$ Nand $m$ Nare proportional to $x$. These two facts imply the following two ordering conditions. If regime $\mathrm{C}$ exists, it must be for the lowest interval of 
$y:\left[z^{\text {Min }}, \bigotimes\right]$. If regimes A or D exist, it must be for the highest interval of $y:\left(s^{*}, 4\right)$, so $\mathrm{A}$ and $\mathrm{D}$ are mutually exclusive. Regime D is also mutually exclusive with regime $\mathrm{B}$, because otherwise the demands for either $k$ Nor $m$ Nwould not be weakly increasing with $y$. Hence Condition 3.1 rules out the existence of regime $\mathrm{D}$. To characterize $s^{*}$ and $\downarrow$, let $x=y=1$, so $k=0$. Denote the optimal choice $\left(c^{*}, m^{*}, k^{*}\right)$. Because marginal utility converges to infinity as consumption converges to zero, both $c^{*}>0$ and $m^{*}+k^{*}>0$. If $k^{*}$ were zero, then $m^{*}>0, c$ Nwould be deterministic, and the investment irreversibility constraint would not bind in the next period with probability one. As a result, conditions (7) to (9) imply $1+r \geq \bar{z}+\mu$, which is a contradiction. Hence $k^{*}>0$. If $m^{*}=0$, then regime $\mathrm{D}$ would exists which has already been ruled out if Condition 3.1 applies. Hence $m^{*}>0$. Let $s^{*}=\mu$ $\left(c^{*}+m^{*}\right) / k^{*}>0$. For $y=s^{*}$ and $k=1$, homogeneity implies $k N=\mu k$ and the interior optimal choice is unhindered by the two inequality constraints. As long as $y>s^{*}$, the interior optimal choice remains unhindered by the inequality constraints, so regime $\mathrm{A}$ applies if $s^{*} \$ z^{\text {Min }}$. If $s^{*} \# z^{\text {Min }}$, regime $\mathrm{A}$ is the only regime for all range of possible values of $y$. In this case, (B) and (C) of part (ii) hold vacously. If $s^{*}>z^{\text {Min }}$, continuity implies that exist $\diamond<\mathrm{s}^{*}$ for which if $y 0\left(\vee, \mathrm{s}^{*}\right]$, then $k \mathrm{~N}=\mu k$ and $m \bowtie 0$. In this interval, regime B applies. As $y$ falls from $s^{*}$ to its minimum value $z^{M i n}, m$ Nmay remain positive in the whole range. In this case, (B) and (C) of part (ii) hold for $\downarrow=0$. If $m \mathrm{~N}=0$ for some $\diamond 0\left[z^{\operatorname{Min}}\right.$, $s^{*}$ ), then regime $\mathrm{C}$ holds for this $\oslash$. This proves part (ii).

To prove part (iii), let $k=1$. I will show that the demand for money is positive at $y=z^{\operatorname{Max}}$ if $z^{\operatorname{Min}}<\operatorname{Min}\left\{z_{1}, z_{2}, z_{3}\right\}$; where $z_{1}=\mu\left(\left[\beta E\left(\mu+z^{\prime}\right)^{1-\sigma}\right]^{\frac{-1}{\sigma}}-1\right), z_{2}=z^{\operatorname{Max}}\left[\operatorname{Pr}\left(z^{\operatorname{Min}}\right) \beta \mu^{1-\sigma}\right]^{1 / \sigma}$, and $z_{3}=\mu\left(1-\beta \mu^{1-\sigma}\right)-E\left(z^{\prime} \mid z^{\prime} \neq z^{M i n}\right)\left[\operatorname{Pr}\left(z^{M i n}\right)^{-1}-1\right]$. (Note this condition does not contradict Assumption 3.1.) This inequality rules out the three logical cases which can arise when $m \aleph=0$ at $y=$ 
$z^{\operatorname{Max}}$. First, $k \bowtie \mu$ both at $y=z^{\operatorname{Max}}$ and $y=z^{\operatorname{Min}}$. In this case, the regime ordering argument in the proof of (ii) implies that $m \aleph=0$ and $k \bowtie \mu$ for all $y$. Second, $k N=\mu$ at $y=z^{\operatorname{Max}}$. In this case, the proof of (ii) implies that $m \aleph=0$ and $k N=\mu$ at $y=z^{M i n}$ as well. And third, $k \aleph \triangleright \mu$ at $y=z^{M a x}$, but $k N=\mu$ at $y=z^{\operatorname{Min}}$.

The condition $z^{\text {Min }}<z_{1}$ rules out the first case by showing that this inequality contradicts that conditions (8) and (9) hold always with equality. If $k \bowtie \mu$ for all $y$, consumption is always proportional to wealth. Let? be the constant of proportionality. Using (8) and (9) with equality, ? can be easily solved to get $\omega=1-\beta\left[E\left(\mu+z^{\prime}\right)^{1-\sigma}\right]^{1 / \sigma}$. The condition $k N \$ \mu k$ is contradicted if $(1-?)\left(\mu+z^{M i n}\right)<\mu$, or equivalently $z^{\text {Min }}<? \mu(1-?)^{-1}=z_{1}$.

The condition $z^{\text {Min }}<z_{2}$ rules out the second case by showing that this inequality contradicts

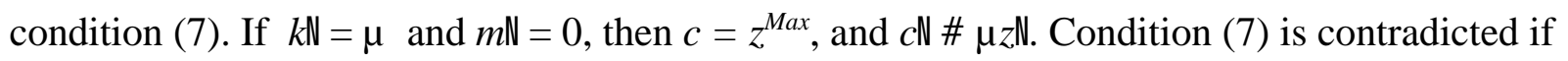
$\left(z^{M a x}\right)^{-\sigma}<\beta(1+r) E\left(\mu z^{\prime}\right)^{-\sigma}$. Hence the second case is ruled out if $z^{\operatorname{Max}}>\left[\beta \mu^{1-\sigma} E z^{-\sigma}\right]^{-1 / \sigma}>\left[\beta \mu^{1-\sigma} \operatorname{Pr}\left(z^{M i n}\right)\right]^{1 / \sigma} z^{\text {Min }}$, which is equivalent to $z^{M i n}<z_{2}$.

The condition $z^{\text {Min }}<z_{3}$ rules out the third case by showing that this inequality contradicts that the individual cannot raise utility by a marginal restructuring of savings from investment to money. The gain from this restructuring is $\Delta=\Delta_{m}-\Delta_{k}$, for $\Delta_{m}=(1+r) E_{0} c_{1}^{-\sigma}$ and $\Delta_{k}=\sum_{t=1}^{\infty}(\beta \mu)^{t-1} E_{0} z_{t} c_{t}^{-\sigma}$. Let $g_{c}$ be the first component of $G(s, 1)$. Using that in this third case the irreversibility constraint is binding when $y / k=z^{\text {Min }}$ and $k \aleph \mu$, the marginal utility of physical investment is recursively bounded above by

$$
\Delta_{k} \leq\left[\operatorname{Pr}\left(z^{\operatorname{Min}}\right)\left[\left(z^{\text {Min }}\right)^{1-\sigma}+\beta \mu \Delta_{k}\right]+\left[1-\operatorname{Pr}\left(z^{\operatorname{Min}}\right)\right] E\left(\left(z^{\prime}+\mu\right)\left[g_{c}\left(z^{\prime}\right)\right]^{-\sigma} \mid z^{\prime} \neq z^{M i n}\right)\right] k^{\prime-\sigma} .
$$

Solving for ${ }_{k}$ and using $k \bowtie \mu$,

$$
\Delta_{k} \leq\left[1-\operatorname{Pr}\left(z^{M i n}\right) \beta \mu^{1-\sigma}\right]^{-1}\left[\operatorname{Pr}\left(z^{M i n}\right) z^{M i n}+\left[1-\operatorname{Pr}\left(z^{M i n}\right)\right] E\left(\left(z^{\prime}+\mu\right)\left[g_{c}\left(z^{\prime}\right)\right]^{-\sigma} \mid z^{\prime} \neq z^{M i n}\right)\right] k^{\prime-\sigma} .
$$


Because $g_{c}$ is increasing (see part [ii]),

$$
E\left(\left(z^{\prime}+\mu\right)\left[g_{c}\left(z^{\prime}\right)\right]^{-\sigma} \mid z^{\prime} \neq z^{M i n}\right)=E\left(\left(z^{\prime}+\mu\right) \mid z^{\prime} \neq z^{\operatorname{Min}}\right) E\left(\left[g_{c}\left(z^{\prime}\right)\right]^{-\sigma} \mid z^{\prime} \neq z^{\text {Min }}\right) .
$$

Using $1+r \$ \mu$, the marginal utility of increasing the money demand is bounded below by

$$
\Delta_{m} \geq \mu \operatorname{Pr}\left(z^{M i n}\right)\left(z^{M i n}\right)^{-\sigma}+\mu\left[1-\operatorname{Pr}\left(z^{M i n}\right)\right] E\left(\left[g_{c}\left(z^{\prime}\right)\right]^{-\sigma} \mid z^{\prime} \neq z^{M i n}\right) .
$$

Finally, combining the last three expressions with the definition of ?, we get $\Delta>0$ if $z_{3}>z^{\operatorname{Min}} \sim$

ProOF OF LEMMA 3.1: If $s \$ s^{*}$ and $z \mathbb{N}=z^{\operatorname{Max}}$, the definition of $s^{* *}$ implies $s \mathrm{~N}=s^{* *}$. If $z^{\operatorname{Max}} \$ s^{*}$, a realization $z N=z^{\operatorname{Max}}$ always leads to $s \mathrm{~N} \$ s^{*}$. Therefore, in this case the probability of a transition from $s_{0}=z^{M i n}$ to $s_{2} \$ s^{* *}$ in two periods is at least $\left[\operatorname{Pr}\left(z^{\operatorname{Max}}\right)\right]^{2}>0$. If $z^{\text {Max }}<s^{*}$, Proposition 3.1 implies that $k \mathrm{~N}=\mu k$, and $m \mathrm{~N}>0$, for all $s \mathrm{O}\left[z^{\operatorname{Max}}, s^{*}\right]$. Also, this proposition implies that $c=g_{c}(s) k$ for a continuous and increasing function $g_{c}$. Thus, for all $s 0\left[z^{\operatorname{Max}}, s^{*}\right]$ condition (7) implies:

$$
\left[g_{c}(s)\right]^{-\sigma}=\beta(1+r) \mu^{-\sigma} E\left[g\left(s^{\prime}\right)\right]^{-\sigma} .
$$

Conditional upon a realization $z \mathrm{~N} \in z^{\operatorname{Max}}$, we have:

$$
\left[g_{c}(s)\right]^{-\sigma}>\beta(1+r) \mu^{-\sigma}\left[g_{c}\left(s^{\prime}\right)\right]^{-\sigma}
$$

Therefore, $g_{c}\left(s \mathbb{N}>g_{c}(s)\right.$ and $s \aleph s$ for all $s 0\left[z^{\operatorname{Max}}, s^{*}\right]$ if $z N=z^{\operatorname{Max}}$ and $B(1+r) \mu^{-s} \$ 1$. Let ? be the minimum $s \mathbb{N}-s>0$ for all $s$ in the compact set $\left[z^{\operatorname{Max}}, s^{*}\right]$. For a consecutive sequence of $z \mathbb{N}=z^{\operatorname{Max}}$ a transition from $s_{0}=z^{\operatorname{Min}}$ to $s_{t} \$ s^{* *}$ would take at most a finite number of periods $N=\left[\left(s^{*}-z^{\operatorname{Max}}\right) /\right.$ ? $]$ +2 . Therefore, the probability of a transition from $s_{0}=z^{M i n}$ to $s_{t} \$ s^{* *}$ in finite time is at least $\left[\operatorname{Pr}\left(z^{M a x}\right)\right]^{N}>0$. Finally, $s^{* *}>s^{*}$, because $s \aleph s$ for $z N=z^{M a x}$ and $y=s^{*}$. Therefore, the probability of a transition from $s^{* *}$ to $s^{* *}$ in a single period is $\operatorname{Pr}\left(z^{\operatorname{Max}}\right)>0$.

The proof of (ii) is analogous to the proof of (i). In this case, condition (7) implies that $s \mathrm{~N} s$ for 
all $s 0\left[z^{\operatorname{Max}}, 4\right)$ if $z N=z^{\operatorname{Min}}$ and $\beta(1+r) \mu^{-s} \# 1$. Let ? be the minimum $s-s \aleph 0$ for all $s$ in the compact set $\left[z^{M a x}, s^{*}\right]$. For a consecutive sequence of $z \mathrm{~N}=z^{\text {Min }}$ a transition from $s_{0}=s^{* *}$ to $s_{t} \# z^{\text {Max }}$ would take at most a finite number of periods $N=\left[\left(s^{*}-z^{\operatorname{Max}}\right) / ?\right]+2$. Therefore, the probability of a transition from $s_{0}=s^{* *}$ to $s_{t} \# z^{M a x}$ in finite time is at least $\left[\operatorname{Pr}\left(z^{\operatorname{Min}}\right)\right]^{N}>0$. Finally, for all $s, s$ Nis at least $z^{\operatorname{Max}}$ if $z \mathrm{~N}=z^{M a x}$, the probability of a transition from $s_{0}=z^{M i n}$ to $s \mathrm{~N} \$ z^{M a x}$ in a single period is at least $\operatorname{Pr}\left(z^{\operatorname{Max}}\right)>0 \sim$

PROOF OF PROPOSITION 3.2: This proof is based on Theorem 12.12 in Stokey, Lucas and Prescott (1989, p.382). Proposition 3.1 implies that $s$ NO $S=\left[z^{\operatorname{Min}}, s^{* *}\right]$ for $s^{* *}$ as defined in Lemma 3.1. The transition function $P$ is clearly monotone given the monotone properties of the optimal solution in Proposition 3.1. Moreover, $P$ satisfies the Feller property because the set of states of $z$ Nis countable. Consequently, with the mixing condition stated in Lemma 3.1 Theorem 12.12 is applicable. This theorem implies that there is an invariant distribution for $s$ and the long run behavior of an individual converges to this invariant distribution. In this distribution, the probability of states with a positive demand for money is positive, because Condition 3.1 implies that the set of states with zero money balances is not absorbent

PROOF OF PROPOSITION 4.1: The function $g_{k}(s)$ is continuous, nondecreasing, and bounded below by $\mu>0$. Thus $?_{n} 6$ ? implies $\int_{S} g_{k}(s) \lambda_{n}(d s) \rightarrow \int_{S} g_{k}(s) \lambda(d s)>0$. Moreover, $\int_{S} g_{k}(s) P\left(s, s^{\prime}\right) \lambda_{n}(d s) \rightarrow \int_{S} g_{k}(s) P\left(s, s^{\prime}\right) \lambda(d s)$ at all continuity points of the distribution function $P\left(s\right.$, @. Therefore, $\lim _{n \rightarrow \infty} T^{*} \lambda_{n}=T^{*} \lambda$ for all continuity points of these distribution functions. This 
proves (i).

Define $S_{\mathrm{o}}=\left[s^{\operatorname{Min}}, s^{*}\right) 1 S$. For all $s 0 S_{0}$, the irreversibility constraint is binding, so $g_{k}(s)=\mu$. Conversely, for all $s \mathrm{O}\left(S-S_{\mathrm{o}}\right)$, the irreversibility constraint is not binding, so $P\left(s, s \mathbb{N}=P\left(s^{*}, s \mathbb{N}\right.\right.$. Consequently, the definition of $T^{*}$ can be simplified as follows:

$$
\left(T^{*} \lambda\right)\left(s^{\prime}\right)=P\left(s^{*}, s^{\prime}\right)+\mu \kappa^{-1} \int_{S_{0}}\left[P\left(s, s^{\prime}\right)-P\left(s^{*}, s^{\prime}\right)\right] \lambda(d s)
$$

where $\kappa=\int_{S} g(s) \lambda(d s)$. Because $g_{k}$ is nondecreasing, $?_{1} \# ?_{2}$ if $?_{1} \$ ?_{2}\left(?_{2}\right.$ stochastically dominates $\left.?_{1}\right)$. Likewise, because $P\left(@ s \mathbb{N}\right.$ is nonincreasing, the integral in (13) is at least as large for ? ${ }_{1}$ than for $?_{2}$. This proves (ii).

For all $s 0\left(S-S_{\mathrm{o}}\right), P\left(s, s \mathbb{N}=P\left(s^{*}, s \mathbb{N}\right.\right.$. Thus equation (13) can be also written:

$$
\left(T^{*} \lambda\right)\left(s^{\prime}\right)=\left(1-\mu \kappa^{-1}\right) P\left(s^{*}, s^{\prime}\right)+\mu \kappa^{-1}\left(T_{i}^{*} \lambda\right)\left(s^{\prime}\right)
$$

The term $\mu ?^{-1} 0(0,1]$, so (14) implies $T_{i}^{*} ? \$ T^{*} ? \$ P\left(s^{*}\right.$, @. If $?\left(s^{*}\right)=1$, then the irreversibility constraint is binding with probability 1 in ?. Consequently, $\mu ?^{-1}=1$ and $T_{i}^{*} ?=T^{*}$ ?. Finally, if $?(s)=0$, the irreversibility constraint is strictly binding with probability zero in ?. Consequently, $P\left(s^{*}, @=T_{i}^{*} ?=\right.$ $T^{*}$ ?. This proves (iii).

Form the sequences $\left\{T^{* n} \mathrm{~d}\left(s^{M i n}\right)\right\}$ and $\left\{T^{* n} \mathrm{~d}\left(s^{* *}\right)\right\}$, where $\mathrm{d}(s)$ is a distribution function that assigns unit probability to $s$. Both sequences converge weakly, and their limits $?^{*}{ }_{1}$ and $?^{*}$ are invariant distributions because $T^{*}$ is continuous and monotone (Stokey, Lucas, and Prescott [1989, Exercise 12.12, p. 381]). For all $?_{0} 0 ?(S), \mathrm{d}\left(s^{\operatorname{Min}}\right) \$ ?_{0} \$ \mathrm{~d}\left(s^{\operatorname{Max}}\right)$. Therefore, the monotone property of $T^{*}$ implies:

$$
T^{* n} \mathrm{~d}\left(s^{M i n}\right) \$ T^{*} ?_{0} \$ T^{* n} \mathrm{~d}\left(s^{M a x}\right), \quad n=1,2, \ldots, \text { all all } ?_{0} 0 ?(S)
$$


If $?^{*}=?^{*}{ }_{2}$, then it follows that the sequence $\left\{T^{*}{ }^{*}{ }_{0}\right\}$ also converges weakly to this common limiting distribution, and this common limit assigns positive probability to high monetary states because of part (iii). Hence to prove the proposition it suffices to prove $?^{*}{ }_{1}=?^{*}$.

Define $S_{\mathrm{o}}=\left[s^{\operatorname{Min}}, s^{*}\right) 1 S$ (set of states where the irreversibility constraint is strictly binding). Suppose the following condition is satisfied:

There is a positive real e and a positive integer $N$ such that $P^{N}\left(s^{\operatorname{Min}}, s^{*}\right)<1$ - e.

Clearly, this condition implies $s^{*}<s^{\operatorname{Max}}$ and $?_{i}^{*}\left(s^{*}\right)<1$. That is, the invariant distribution for an individual $?^{*}$ assigns positive probability to the complement of $S_{0}$. Moreover, part (iii) implies $T^{* n} \mathrm{~d}\left(s^{M i n}\right)\left(s^{*}\right) \# T_{i}^{* n} \mathrm{~d}\left(s^{M i n}\right)\left(s^{*}\right)$, so $?_{1}{ }_{1}^{*}\left(s^{*}\right) \# ?_{i}^{*}\left(s^{*}\right)<1$ because of continuity. Because $?^{*}{ }_{1}$ and $?^{*}{ }_{2}$ are finite measures, there is a triple of measures $\mathrm{a}_{0}, \mathrm{a}_{1}$, and $\mathrm{a}_{2}$ such that $?^{*}{ }_{1}=\mathrm{a}_{0}+\mathrm{a}_{1}, ?^{*}{ }_{2}=\mathrm{a}_{0}+\mathrm{a}_{2}$, and $\mathrm{a}_{1}$ and $\mathrm{a}_{2}$ are mutually singular. For all $s \mathrm{NO} S$, the following expression holds:

$$
\begin{aligned}
\mid \lambda_{1}^{*}\left(s^{\prime}\right)- & \lambda_{2}^{*}\left(s^{\prime}\right) \mid \\
& =T^{*} \lambda_{1}^{*}\left(s^{\prime}\right)-T^{*} \lambda_{2}^{*}\left(s^{\prime}\right) \\
& =\mu \kappa_{1}^{-1} \int_{S_{0}}\left[P\left(s, s^{\prime}\right)-P\left(s^{*}, s^{\prime}\right)\right] \lambda_{1}^{*}(d s)-\mu \kappa_{2}^{-1} \int_{S_{0}}\left[P\left(s, s^{\prime}\right)-P\left(s^{*}, s^{\prime}\right)\right] \lambda_{2}^{*}(d s) \\
& =\mu \kappa_{1}^{-1} \int_{S_{0}}\left[P\left(s, s^{\prime}\right)-P\left(s^{*}, s^{\prime}\right)\right] \alpha_{1}^{*}(d s)-\mu \kappa_{2}^{-1} \int_{S_{0}}\left[P\left(s, s^{\prime}\right)-P\left(s^{*}, s^{\prime}\right)\right] \alpha_{2}^{*}(d s) \\
& \leq \mu \kappa_{1}^{-1}\left[P\left(s^{M i n}, s^{\prime}\right)-P\left(s^{*}, s^{\prime}\right)\right] \int_{S_{0}} \alpha_{1}^{*}(d s) \\
& \leq \mu \kappa_{1}^{-1}\left\|\lambda_{1}^{*}-\lambda_{2}^{*}\right\| .
\end{aligned}
$$

In this expression, the second line uses $?_{1}{ }^{*}$ and $?_{2}{ }^{*}$ are invariant distributions with $T^{*}, ?_{1}{ }^{*} \$ ?_{2}{ }^{*}$, and $T^{*}$ is monotone. The third line uses (13). The fourth line uses that $\mathrm{a}_{0}$ is common to both $?_{1}{ }_{1}$ and $?_{2}{ }^{*}$. The fifth line uses $P\left(s^{\operatorname{Min}}, s \mathbb{N} \$ P\left(s, s \mathbb{N} \$ P\left(s^{*}, s \mathbb{N}\right.\right.\right.$ for all $s$ and $s$ Nin $S_{0}$. The sixth line uses $\left[P\left(s^{\operatorname{Min}}, s \mathbb{N}-\right.\right.$ $P\left(s^{*}, s \mathbb{N}\right] 0[0,1]$, and the definitions of $\mathrm{a}_{1}$ and $2 @$ Because $?_{1}>\mu$ expression (16) implies $2 ?_{1}{ }^{*}-?{ }_{2}{ }^{*} 2=$ 
0 , so $?_{1}{ }^{*}=?_{2}{ }^{*}$. This proves uniqueness if condition (15) is satisfied. If this condition is not satisfied, $s^{*} \$ s^{M a x}$ and $S=S_{0}$. That is, the irreversibility constraint is always binding in the invariant distributions for $T^{*}$ and $T_{i}^{*}$. Part (iii) implies that for the whole range $S$, these two operators are identical, so $?_{\mathrm{i}}^{*}=?_{1}^{*}=?_{2}^{*} \sim$

PROOF OF PROPOSITION 4.2: Individual behavior changes continuously with $r$, so Theorem 12.13 in Stokey, Lucas and Prescott (1989, p. 384) implies that the invariant distributions are also continuous with respect to $r$. The market clearing condition (7) is satisfied if $r=g$. Hence it suffices to prove that there is a pair $r_{1}$ and $r_{2}$ in the range $[1-\mu, \bar{z}-(1-\mu))$ for which $r_{1} \# g_{1}$, and $r_{2} \$ g_{2}$. The inequality $r_{1} \# g_{1}$ is clearly satisfied for $r_{1}=1-\mu$, because the rate of growth of capital is bounded below by $\mu$. For $r_{3}=\bar{z}-(1-\mu)$, individuals hold no capital (see proof of Proposition 5.1), so the wealth of all individuals would grow at a common deterministic rate $g_{3}=\left[\beta\left(1+r_{3}\right)\right]^{1 / \sigma}-1<r_{3}($ the last inequality follows from Assumption 3.1). Continuity of the set of feasible consumption paths with respect to $r$ at $r_{3}$ implies the existence of $r_{2}<\bar{z}-(1-\mu)$ sufficiently close to $r_{3}$ for which $g_{2}<r_{2} \sim$

ProOF OF PROPOSITION 5.1: Suppose an individual were to invest in capital when the optimum quantity is pursued. Condition (8) should hold with equality, so together with (7) to (9) implies:

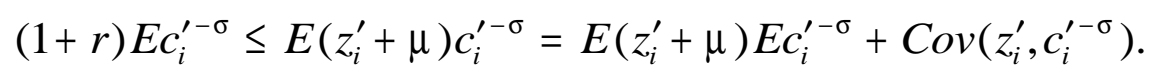

The normality of consumption (preferences are homogeneous) implies that the covariance term in (17) is negative. Consequently, as long as private gross investment is positive, the return on money is lower than the expected return on capital: $r<\bar{z}-(1-\mu)$. This would contradict that the optimum quantity 
is pursued. Therefore, private gross investment must be zero. As the only balanced path equilibrium without private capital investment is one without private capital. This proves (i).

Suppose the government reduces the money supply with the proceeds from taxes and the ownership of a portion of the capital stock. The government's flow budget states that the expenditure on public investment and reduction on the money supply must be equal to the revenue from public capital income and taxes:

$$
K_{g}^{\prime}+\left(\frac{M_{N}-M_{N}^{\prime}}{p}\right)=K_{g} r_{g}+T_{g} ;
$$

where $K_{g}=$ the aggregate capital owned by he government; and

$$
T_{g}=\text { current real taxes collected by the government. }
$$

Along a balanced path equilibrium where $r=\bar{z}-(1-\mu)$ and all real variables grow at the rate $g$, this budget constraint simplifies to:

$$
M(r-g)=K_{g}\left(r_{g}-g\right)+T_{g} .
$$

Dividing by $r$ - $g$, this equation is transformed into:

$$
M=K_{g} \frac{r_{g}-g}{r-g}+\frac{T_{g}}{r-g} .
$$

Consequently, the money supply is backed with the present value of the net cash flow from public capital plus the present value of future taxes, both discounted at the rate $r$. This proves (ii).

As part (1) shows, in a balanced path where $r=\bar{z}-(1-\mu)$ all capital is publicly owned, so the effective return on capital along this balanced path is $r_{g}$. As part (ii) implies, money can only earn a higher return than $r_{g}$ if the government collects lump-sum taxes to subsidize the monetary system. This policy is clearly inefficient as it leads to a disparity between the marginal rates of substitution and transformation between present and future output. Furthermore, if the lump-sum taxes are non 
redistributive (proportional to the wealth of private individuals), a Pareto improvement can be achieved with a monetary reform that cancels taxes and maintains money fully backed with public capital. That is, a monetary reform that changes the return on money from $\bar{z}-(1-\mu)$ to $r_{g}$. This reform is a Pareto improvement because with money being fully backed with public capital holding money is equivalent to holding public capital. If an individual were to choose not to invest in his/her private technology, the optimal deterministic path with a net rate of return on wealth equal to $r_{g}$ is both feasible and superior to the deterministic path for this individual before the reform as it eliminates the distortion between the marginal rates of substitution and transformation. The fact that the individual can invest in his/her private technology further improves his/her well being after the reform 


\section{REFERENCES}

1. S. R. Aiyagari and M. Gertler, Asset returns with transactions costs and uninsured individual risk, J. Monet. Econ. 27 (1991), 311-331.

2. F. Alvarez and N. Stokey, Dynamic progamming with homogeneous functions, J. Econ. Theory 82 (1998), 167-189.

3. R. Barro, Government spending in a simple model of endogenous growth, J. Polit. Economy. 98 (1990), S103-S125.

4. T. Bewley, The optimum quantity of money, in "Models of Monetary Economies" (J. H. Kareken and N. Wallace, Eds.), pp. 169-210, Federal Reserve Bank of Minneapolis, Minneapolis, 1980.

5. T. Bewley, A difficulty with the optimum quantity of money, Econometrica 59 (1983), 1581-1589.

6. M. Faig, "Money with Idiosyncratic Uninsurable Returns to Capital," Working Paper No. FAIG0001 (http://www.chass.utoronto.ca/ecipa/archive/UT-ECIPA-FAIG-00-01.html), University of Toronto, 2000.

7. M. Faig, The optimal structure of liquidity provided by a self-financed central bank, J. Money, Credit, Banking, forthcoming (2000).

8. M. Feldman and C. Gilles, An expository note on individual risk without aggregate uncertainty, $J$. Econ. Theory 35 (1985), 26-32.

9. D. K. Foley and M. Hellwig, Asset management with trading uncertainty, Rev. Econ. Stud. 42 (1975), 327-46.

10. M. Friedman, The optimum quantity of money, in "The Optimum Quantity of Money and Other 
Essays," pp. 1-50, Aldine, Chicago, 1969.

11. M. Hugget, The risk-free rate in heterogeneous-agent incomplete-insurance economies, J. Econ. Dynam.Control 17 (1993), 953-69.

12. K. Judd, The law of large numbers with a continuum of iid random variables, J. Econ. Theory $\mathbf{3 5}$ (1985), 19-25.

13. T. J. Kehoe, D.K. Levine, and M. Woodford, The optimum quantity of money revisited, in "Economic Analysis of Markets and Games, Essays in Honor of Frank Hahn" (P. Dasgupta, D. Gale, O. Hart, and E. Maskin, Eds.), pp. 501-526, MIT Press, Cambridge, 1992.

14. N. Kiyotaki, R.Wright, A search-theoretic approach to monetary economics, Amer. Econ. Rev. 83 (1993), 63-77.

15. D. K. Levine, Asset trading mechanisms and expansionary policy, J. Econ. Theory 54 (1991), $148-164$.

16. R. E. Lucas, Equilibrium in a pure currency economy, in "Models of Monetary Economies" (J. H. Kareken and N. Wallace, Eds.), pp. 131-146, Federal Reserve Bank of Minneapolis, Minneapolis, 1980.

17. P. Mehrling, A note on the optimum quantity of money, J. Math. Econ. 24 (1995), 249-258.

18. N. L. Stokey, R. E. Lucas, and E.C. Prescott, "Recursive Methods in Economic Dynamics," Harvard University Press, Cambridge, Massachusetts, 1989.

19. B. Taub, Efficiency in a pure currency economy with inflation, Econ. Inquiry 26 (1988), 567-583.

20. R. Townsend, Models of money with spatially separated agents, in "Models of Monetary Economies" (J. H. Kareken and N. Wallace, Eds.), pp. 265-303, Federal Reserve Bank of 
Minneapolis, Minneapolis, 1980.

21. M. Woodford, Public debt as private liquidity, Amer. Econ. Rev. 80 (1990), 382-288. 


\section{NOTES}

1.Growth is endogenous because production functions are linear in capital as in [3].

2.Several other papers have also added capital to Bewley's model [4], for example: [1, 11, 21].

3.Independence across individuals would provide an intuitive and widely used device to eliminate aggregate risk. However, this type of independence with a continuum of individuals leads to technical difficulties. (See $[8,12])$.

4.See [4] for references to earlier work advocating this rule.

5.See Proposition 2 p. 29 in [8] for the consistency of this assumption when independence across individuals is not imposed.

6.See for example [14, Section I] where multiplicity of equilibria is discussed at depth in a random matching model.

7. These conditions already incorporate that the inequality constraints in (2) will never bind for $c$. 8.In this equilibrium, taxes may be zero and then the money supply is fully backed with public capital. However, this is not necessarily the case, since the government may induce private individuals to hold additional quantities of money, which is the only public debt instrument in the model, by making them pay taxes in the future. If these taxes cause no direct incentive effects and do not redistribute wealth, the taxes will just raise the initial real holdings of money without any consequence for the real variables in the economy. Thus, this version of Ricardian Equivalence applies in the present equilibrium. 9.[1] assumes that human capital cannot be accumulated, thus precluding endogenous growth. 10.I am grateful to an anonymous referee for suggesting and encouraging this line of work. 